\section{BioShield defence programme set to fund anthrax vaccine}

Erika Check, Washington

A US government programme to bolster public defences against bioterrorism will soon give out its first grants - despite complaints from the biotechnology industry that the programme is not working as intended.

An official at the Department of Health and Human Services says it is reviewing proposals for a nextgeneration anthrax vaccine and expects to fund one of them this year under the BioShield programme. Congress allocated $\$ 890$ million to the programme in 2004, but biotechnology companies say the money has not materialized.

Project BioShield was first proposed by President George Bush in his State of the Union Address in January 2003. He said the programme would spend \$5.6 billion over ten years on developing products, such as vaccines, that could be used in response to bioterrorist attacks. Bush said the money would give companies an incentive to test and manufacture products that might not otherwise have a commercial market.

But even though Congress has given the health department funding for BioShield in 2004, it has not yet passed legislation setting out detailed rules for how the money should be spent, leaving many questions unanswered about the programme's future.

Companies have complained about the delay in passing the legislation. They say that uncertainty over the programme is stopping them from conducting late-stage trials of potential therapies. For instance, Human Genome Sciences of Rockville, Maryland, says that it has halted development of a monoclonal antibody that could be used against anthrax.

"We have delivered what we thought the government was looking for, but we are at a point now where we would require a considerably larger investment and we are not able to do that without a government commitment," says Jerry Parrott, a spokesman for the company.

But officials at the health department say the rules for implementing BioShield are already clear. They say the 2004 funding legislation laid out some guidance for the programme, and that department officials already have the experience needed to grant BioShield contracts.

"This is important and the money is there, so we feel we would be remiss if we did not use it as Congress intended," says one department official.

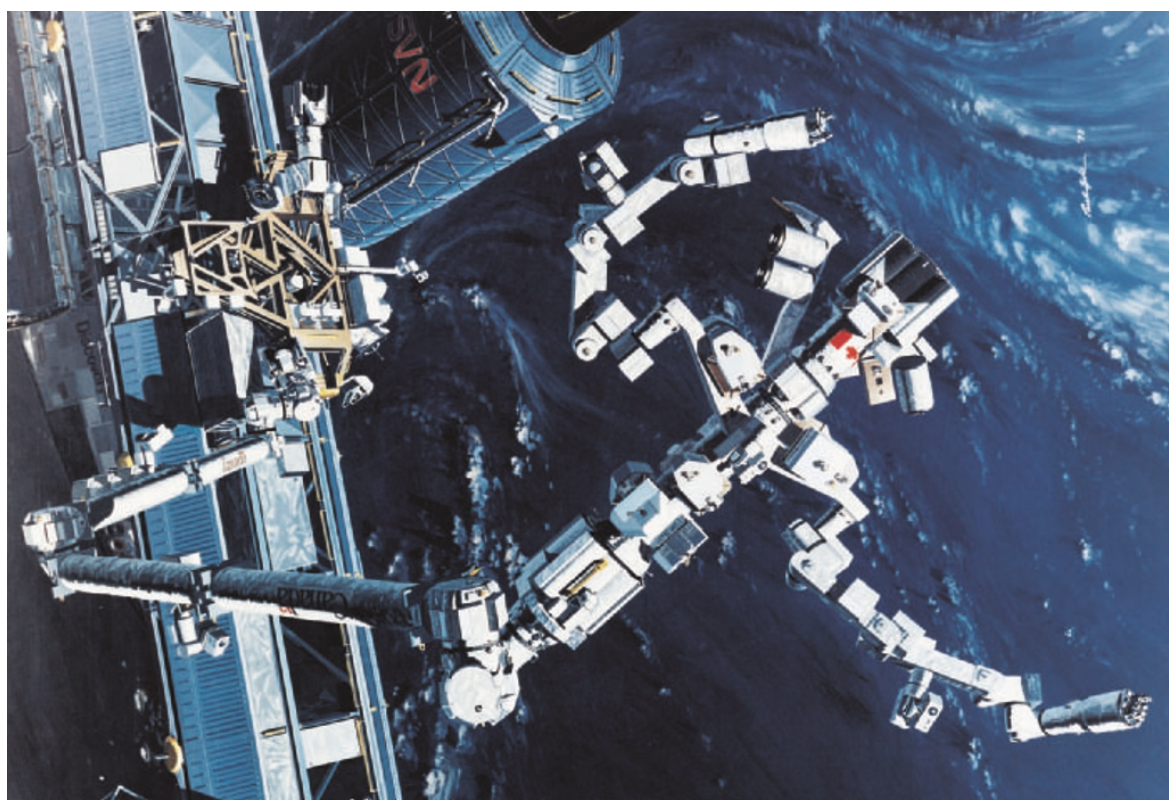

Automatic for the people: machines could take the place of humans to help Hubble.

\title{
NASA opens its arms to robot options for saving telescope
}

Tony Reichhardt, Washington

A plan to use robots instead of astronauts to rescue the Hubble Space Telescope moved closer to approval last week, when NASA announced that it would solicit industry proposals for part of a salvage mission.

Scientists who were initially sceptical of relying on robots for the job say it now looks feasible - provided the agency comes up with several hundred millions of dollars to pay for it.

Engineers from seven NASA centres will gather at the Goddard Space Flight Center in Maryland on 13-14 May to review plans, recently developed there, to service the telescope robotically. Hubble's batteries are expected to fail at some point in 2008 or 2009.

If the review is favourable, NASA will request bids on 1 June for robotically deorbiting the telescope to prevent it crashing to Earth. And, says Hubble programme manager Preston Burch, the agency is now "very optimistic" about attaching a robot to upgrade Hubble's instruments and extend its lifetime (see Nature 428, 353; 2004).

NASA officials seem to prefer the Special Purpose Dexterous Manipulator (Dextre), a two-armed robot built by MD Robotics of Brampton, Ontario, which they plan to install on the International Space Station in 2007. Other contenders for the job are not technically mature or have never flown in space, says Burch.

Dextre is already fully built and was derived from proven hardware: the space shuttle's robot arm, which has been used successfully for more than 20 years. MD Robotics has loaned Goddard the use of test equipment, and initial simulations of Hubble repair tasks have been very encouraging, says Burch.

Finance remains an issue, however. Even the deorbit-only mission - which involves attaching a propulsion module to Hubble and steering it into the ocean - has an estimated cost of at least US\$500 million, including a launch vehicle. Adding Dextre or another robot to service the telescope would require a bigger launch vehicle, which would raise the price, says Burch. But robotic servicing would still be cheaper than sending space shuttle astronauts to do the job.

Steven Beckwith, director of the Space Telescope Science Institute in Baltimore, worries that NASA might settle for "half a loaf" and only do the bare-bones deorbit or minimal repairs, as he estimates that a full servicing mission will cost "a large fraction of a billion dollars". But although he and other astronomers originally argued that astronauts were necessary for the full servicing job, they now accept that the robotic repair is technically feasible. According to Burch, a briefing of the Hubble Space Telescope Users Committee late last month convinced members that the technology could work.

Beckwith still thinks astronaut servicing has the "highest probability of succeeding", however. A National Academies panel formed to look at options for extending Hubble's life will consider both human and robotic servicing. The panel, chaired by Louis Lanzerotti, an astrophysicist and consultant with Bell Laboratories, will have its first meeting next month and will report in November. 